\title{
Assessment of Environmental Radiation Hazard on Public Health around BSMMU Campus, Dhaka, Bangladesh
}

\author{
Faria Hassan ${ }^{1}$, M. S. Rahman ${ }^{2}$, Shafi M Tareq ${ }^{3}$, S. Yeasmin ${ }^{4}$ \\ ${ }^{1,3}$ Department of Environmental Sciences, Jahangirnagar University, Bangladesh \\ ${ }^{2,4}$ Health Physics Division, Atomic Energy Centre, Bangladesh \\ *(msrahman74@gmail.com)
}

This journal is licensed under a Creative Commons Attribution-NonCommercial 4.0 International License (CC-BY-NC). Articles can be read and shared for noncommercial purposes under the following conditions:

- BY: Attribution must be given to the original source (Attribution)

- NC: Works may not be used for commercial purposes (Noncommercial)

This license lets others remix, tweak, and build upon your work non-commercially, and although their new works must also acknowledge you and be non-commercial, they don't have to license their derivative works on the same terms.

License Deed Link: http://creativecommons.org/licenses/by-nc/4.0/

Legal Code Link: http://creativecommons.org/licenses/by-nc/4.0/legalcode

$A B C$ Research Alert uses the CC BY-NC to protect the author's work from misuse.

\section{Abstract}

Objective: Medical institution uses ionizing radiation for diagnosis or treatment by using ionizing radiation generating equipments such as X-ray machines, CT, PET scan etc. and radioactive materials especially in nuclear medicine centers. The purpose of the study is to monitor the real-time radiation around the Bangabandhu Sheikh Mujib Medical University (BSMMU) campus of Bangladesh for minimizing the ionizing radiation hazard on public health and the environment. Method: The radiation monitoring was performed using real-time portable digital radiation monitoring device. This real-time digital portable radiation monitoring device meets all European CE standards as well as the American "FCC 15 standard". The portable radiation monitoring device was placed at 1 meter above the ground on tripod and data acquisition time for each monitoring point (MP) was 1 hour. 32 MPs were selected for collection of radiation dose rates around BSMMU campus from March-May 2019.

Results: The measured dose rate around the BSMMU campus ranged from 0.02-3.15 $\mu \mathrm{Sv} / \mathrm{hr}$ with an average of $1.452 \pm 0.883 \mu \mathrm{Sv} / \mathrm{hr}$. The annual effective dose were ranged from $0.117 \pm 0.058$ $\mathrm{mSv}$ to $5.445 \pm 0.045 \mathrm{mSv}$ with an average of $2.54 \pm 1.566 \mathrm{mSv}$. The excess life-time cancer risk (ELCR) was estimated which ranged from $4 \times 10^{\wedge}-4$ to $2 \times 10^{\wedge}-2$ with an average value of $1 \times 10^{\wedge}-2$ for 32 selected locations around BSMMU campus.

Conclusion: Dose monitoring helps to ensure the best possible protection of the radiation workers, patients and the general public and provides an immediate indication of incorrect use of technical parameters or equipments malfunction. Not only that, it is also essential to use adequate amount of protective shielding for minimizing radiation hazard on public health and the environment from the scattering radiation of the hospital.

\section{Keywords}

Ionizing radiation, In-Situ, Public Health, Cancer, Gamma Scout

\section{INTRODUCTION}

Environmental Radiation has always been a natural part of our environment. Natural radioactive sources in the soil, water and air contribute to our exposure to ionizing radiation, as well as man-made sources such as nuclear power plants, hospitals, industries, radioactive waste management facilities, consumer 
products, etc. As investment volumes continue to grow in the globalized economy, environmental shadows are intersecting more and more on this planet. The concept of sustainable development, which generally means meeting the needs of the present without assaulting the rights of future generations, is addressed and implemented by many countries to manage the environment in an equal manner. However, there are some nations that achieve growth for their economies without regard to the adverse effects on the open environment. Nuclear and related applications became available everywhere to solve many problems of humanity. These applications, if not managed correctly, may lead to adverse effects of contaminating our environment by adding radioactive materials to already existing radioactivity of natural origin (Isam Salih Mohamed Musa, 2019). In high background radiation areas (HBRAs), the absorbed dose can be as high as 10 times that of normal background areas (Hendry Jolyon $\mathrm{H}$ et al., 2009). It is a well-known fact that the member of public receives an average radiation exposure of 2.4 $\mathrm{mSv}$ per annum with a range of 1-13 mSv/yr (UNSCEAR, 2000). The medical use of ionizing radiation, while offering great benefit to patients, also contributes significantly to radiation exposure of workers and the populations (UNSCEAR, 2000), (EURATOM, 1997), (UNSCEAR, 1993). Some of the health effects of long term exposure to radiation and the inhalation/ingestion of radionuclides are chronic lung disease, acute leucopoenia, anemia necrosis of the mouth, cataract, chronic lung cancer and leukemia (Qureshi et al., 2014), (Ononugbo et al., 2016). Radiation tends to create a higher percentage of double strand breaks than other metabolic damage mechanisms in the DNA molecule. These double breaks are harder to repair. However, even after allowance for this fact, the total number of unrepaired or misrepaired DNA molecules from low-level radiation damage is insignificant compared with those from normal metabolism. Research and biological knowledge of molecular and cellular mechanisms confirm that cancer is a highly complex multi-step process. This makes unlikely the hypothesis that low-level radiation, or any contributor to DNA damage, can contribute linearly to cancer incidence (including linear- quadratic) (Pollycove, et al., 2009), (Trosko, et al., 1996). A damage to the DNA results in gene mutation, chromosomal aberration and breakages or cell death (Emelue, et al, 2014). Most researchers estimate the ELCR (Excess Life-time Cancer Risk) as the product of annual effective dose, life span ( $\sim 70$ years). It is now clear that the rate of incidence of the disease for an unexposed (radiation) population in absolute terms is nonexistent. The unexposed population could be from the well known normal background regions but members of public living in HBRA continue to receive annual exposures of at least 10-20 times higher than those living in normal background areas (Rao, D.D, 2016). No matter how low the exposures are, low level exposures will carry very high uncertainties. If one calculates ELCRs for these regions, they would be certainly high that many times, if corrections are not applied particularly, for adaptation and also uncertainties at low level exposures are unaccounted (Rao, D.D, 2016). The objective of the present study is to monitor the real-time gamma radiation dose rate around BSMMU campus by In-Situ Method using gamma-scout detector. Real-time gamma-radiation measurement is essential for minimizing the radiation hazard in and around the hospital environment and thereby improving the public health.

\section{MATERIALS AND METHODS}

\section{Description of the apparatus}

A real-time digital portable radiation monitoring device which is known as GAMMA SCOUT was used for this study. GAMMA SCOUT is German designed and manufactured, built with a solid Novadur exterior. An optional stylish leather holster with belt strap can further protect the GAMMA SCOUT from the elements. The GAMMA SCOUT is a fully featured Geiger counter with a form fitting ergonomic shape. The unit has a battery indicator, multiple unit conversion, real-time dose rate and cumulative dose display functions and programmable logging and alert functions. Advanced functions include PC data download via USB cable and an ultra-low current power circuit for extended battery life. GAMMA-SCOUT reports the input of radioactivity fast, reliably, and permanently. The conversion of pulses per minute to dose rate depends on the level of pulse input. We are using four different ratios to approximate this nonlinear relation. Under environmental input (about $0.200 \mu \mathrm{Sv} / \mathrm{h}$ ) the conversion 
is $142 \mathrm{pulses} /$ minute $=1.0 \mu \mathrm{Sv} / \mathrm{h}$ (User Manual-GAMMA SCOUT, 2014). Gamma-Scout also provides information on the cumulative dose received by the device, measured on the time axis. As described below, users can stop summation, restart from an old level or delete and restart from zero. Because of this and other reasons, the accumulated dose cannot be used as a certified "personal dose meter." GAMMA-SCOUT w/ALERT features can acoustic signal that sounds when the dose rate exceeds a specific level. The default alert level is $5 \mu \mathrm{Sv} / \mathrm{h}$. If this value is exceeded by measurement of radioactivity, this will be shown with an additional symbol in the display. The symbol in the display can be erased by pressing the button twice. Individual Programming of Dose Rate Alert Level by pressing the button once to switch to the "log frequency" mode. Pressing the button a second time switches the device to "alert level" mode. The set level shows in the display. Pressing the "or" the button to increase or decrease the threshold respectively. The new value appears blinking in the display. The lowest possible threshold setting is $0.1 \mu \mathrm{Sv} / \mathrm{h}$, the maximum is $2 \mathrm{mSv} / \mathrm{h}$. The step change is $0.1 \mu \mathrm{Sv} / \mathrm{h}$ at the lower level, becoming wider higher up the range. If the OFF setting is selected, the dose rate alarm is disabled.

\section{Calibration of the apparatus}

Under environmental radiation, the counter tube is not subject to fatigue and, therefore, will not require re-calibration. However, if the user holds ISO certification, periodical calibration is mandatory. To sub-contract to an assembly operation, which tests it for 72 hours against a master? The master is calibrated against a gauged reference source (Cs-137). A data log is then generated. To the best of our knowledge, this record is accepted as compliant by ISO auditors without exception.

The GAMMA SCOUT was calibrated inbuilt by the manufacturer. The GAMMA SCOUT is also calibrated at the Secondary Standard Dosimetry Laboratory (SSDL) under the Bangladesh Atomic Energy Commission (BAEC) using gamma-ray standard sources such as ${ }^{137} \mathrm{Cs}$, ${ }^{60} \mathrm{Co}$, etc. and X-ray Unit. The SSDL of BAEC has been available since 1991, which is traceable to the Primary Standard Dosimetry Laboratory (PSDL) of National Physical Laboratory (NPL), UK. The SSDL of BAEC has $\mathrm{X}$-ray Unit $(30 \mathrm{kV}-225 \mathrm{kV})$ for radiation generating equipments calibration. The performance of BAEC's SSDL is maintained according to the requirements of the International Atomic Energy Agency (IAEA)/World Health Organization (WHO) network of SSDLs. Therefore, the evaluated doses are traceable to the International measurement system. The GAMMA SCOUT accurately measure dose rate in the range of 0.01-5000 $\mu \mathrm{Sv} / \mathrm{hr}$ (User Manual-GAMMA SCOUT, 2014).

\section{Data collection}

The study was conducted in the months of March-May, 2019. The monitoring of gamma radiation around BSMMU campus was done due to the assumption that the radiations coming from the hospitals where different kinds of radiation generating equipments and radioactive material are being used for diagnostic \& therapeutic purposes of patients which has negative effects on people around the BSMMU campus regularly. Radiation monitoring was performed at the thirty two (32) selected locations around BSMMU Campus under Shahbag Thana of Dhaka city. The gamma radiation dose rate around BSMMU campus was measured for approximately 1 hour for each monitoring place using digital portable Gamma-Scout detector through In-Situ method. The detector was set on a tripod table at $1 \mathrm{~m}$ height from the ground level. The study location was marked out using GARMIN eTrex HC series personal navigator. The unit uses the proven performance of Garmin high-sensitivity GPS and full-featured mapping to create an unsurpassed portable GPS receiver (Owner's Manual-GARMIN eTrex HC Series, 2007).

\section{Description of the Site}

The study site is located from N: 23.74094 to N: 23.73862 and from E: 090.39404 to E: 90.39496 . BSMMU complex has five main multistoried buildings that are identified as Block-A, Block-B, Block-C, Block-D and Block -E as Cabin block respectively (BSMMU website, 2020). Block-A is a 7 
storied building and accommodates the library, lecture theater, auditorium, hospital record section, students hostel, dental faculty and blood transfusion services. The library has a fairly large collection of current and back volumes of periodicals, textbooks, monographs and other related material. Block-B is a 6 storied building which at its eastern wing accommodates the office of the ViceChancellor, administrative block, Controller Office, reception, conference hall, radiology department, digital library, hospital kitchen, maintenance department stores, endoscopy room, CT scan \& MRI room, residential accommodation for the duty doctors and nurses. The western part of Block-B is a 9 storied building and accommodates all the departments of basic medical sciences such as Anatomy, Physiology, Biochemistry, Pharmacology, Pathology, Hematology, Virology and Microbiology. A one-stop laboratory services is located at the ground floor. The animal house is located near this Bblock in a separate building. Block-C is the 10 storied main hospital building. This block accommodates the Office of the Director of hospital and his administration, reception, telephone exchange, departments of Physical medicine, Pediatrics, Neonatology, Pediatric neurology, Pediatric surgery, Clinical pathology, Dermatology, Nephrology, Urology, Neurology, Neuro-Surgery, Ophthalmology, ENT, Obstetrics \& Gynecology, Surgery, Hepatobiliary Surgery, Lithotripsy room, Operation theater, Anesthesiology, Pain clinic, Intensive Care Unit (ICU) \& Post-operative ward. Block-D is the 18 storied building (under construction). This block accommodates the Emergency, Casualty, Cardiac emergency, Obstetrics \& Gynecology emergency, Orthopedics emergency, Cardiology, Cath Lab, CCU, Cardiac surgery, Vascular surgery, Pediatric hematology \& Oncology, Pediatric Cardiology, Pediatric Gastroenterology, Hepatology, Orthopedics, Phychiatry, Gastroenterology, Hematology, Medicine, Oncology \& National Institute of Nuclear Medicine and Allied Sciences (NINMAS) a joint project of Bangladesh Atomic Energy Commission and BSMMU. The NINMAS has modern diagnostic and therapeutic facilities including computerized ultrasonography, gamma camera and a well-equipped radioimmunoassay (RIA) laboratory. This is considered to be the best center for non-invasive diagnoses. Block-E is Cabin Block, OPD 1 \& OPD 2.The causality department, out-patient departments for Medicine, Surgery, Neuro surgery, Neurology, Gastroenterology, Hematology, Psychiatry, Pediatric surgery and Hospital dispensary are located in a separate complex. The goal of the institution is to achieve a high standard in medical education, practice and research and develop human resources for health to ensure quality health care to the people of Bangladesh as well as South Asia Region.

\section{Calculation of Annual effective dose and ELCR}

United Nations Scientific Committee on the Effects of Atomic Radiation (UNCEAR, 1988) recommended the outdoor occupancy factor of 0.20 to population. This occupancy factor is the proportion of the total time during which an individual is exposed to a radiation at outdoor. The outdoor annual effective dose to population due to radiation is calculated according to the following equation: Annual effective dose $(\mu \mathrm{Sv})=$ dose rate $\left(\mu \mathrm{Sv} \cdot \mathrm{hr}^{-1}\right) \times 0.2 \times 8760 \mathrm{hr} \cdot \mathrm{yr}^{-1}$ Excess life-time cancer risk factor (ELCR) is calculated by using the following equation:

$$
E L C R=A E D \times D L \times R F
$$

Where AED is annual effective dose to public, DL is the duration of life of Bangladeshi people (http://en.worldstat.info/Asia/Bangladesh, 2019) and RF is the risk factor $\left(\mathrm{Sv}^{-1}\right)$, it is a fatal cancer risk per Sievert. For stochastic effects from low dose radiation, ICRP 103 suggested the value of 0.057 for the public exposure (ICRP, 2007).

\section{RESULTS AND DISCUSSION}

The measured dose rate around the BSMMU campus ranged from $0.02-3.15 \mu \mathrm{Sv} / \mathrm{hr}$ with an average of $1.452 \pm 0.883 \mu \mathrm{Sv} / \mathrm{hr}$. The annual effective dose were ranged from $0.117 \pm 0.058 \mathrm{mSv}$ to $5.445 \pm 0.045$ $\mathrm{mSv}$ with an average of $2.54 \pm 1.566 \mathrm{mSv}$. Dose monitoring helps to ensure the best possible protection of the radiation workers, patients and general public and provides an immediate indication of incorrect use of technical parameters or equipment malfunction. Not only that, it is also essential to use adequate amount of protective shielding which prevents the scattering of radiation. Table- 1 shows Gamma-ray dose rate measurement around BSMMU campus from March-May, 2019 in 32 locations. 


\begin{tabular}{|c|c|c|c|c|c|c|}
\hline \multirow{2}{*}{$\begin{array}{c}\text { Sl } \\
\text { No. }\end{array}$} & \multirow[t]{2}{*}{ Latitude } & \multirow[t]{2}{*}{ Altitude } & \multicolumn{3}{|c|}{ Radiation dose rate $(\mu \mathrm{Sv} / \mathrm{hr})$} & \multirow{2}{*}{$\begin{array}{l}\text { Annual effective } \\
\text { dose due to } \\
\text { radiation } \\
(\mathrm{mSv}) \pm \mathrm{SD}\end{array}$} \\
\hline & & & Mean & Range & SD & \\
\hline 1 & $\mathrm{~N} 23.74094$ & E090.39404 & 1.386 & $1.362-1.418$ & 0.019 & $2.428 \pm 0.032$ \\
\hline 2 & $\mathrm{~N} 23.74094$ & E090.39421 & 1.439 & $1.411-1.471$ & 0.021 & $2.521 \pm 0.037$ \\
\hline 3 & $\mathrm{~N} 23.74109$ & E090.39469 & 1.515 & $1.482-1.552$ & 0.022 & $2.654 \pm 0.039$ \\
\hline 4 & $\mathrm{~N} 2.741254$ & E090.39517 & 1.556 & $1.543-1.553$ & 0.009 & $2.715 \pm 0.016$ \\
\hline 5 & $\mathrm{~N} 23.74127$ & E090.39547 & 1.568 & $1.554-1.595$ & 0.014 & $2.747 \pm 0.024$ \\
\hline 6 & $\mathrm{~N} 23.74123$ & E090.39571 & 1.589 & $1.513-1.594$ & 0.147 & $2.783 \pm 0.258$ \\
\hline 7 & $\mathrm{~N} 23.74129$ & E090.39565 & 2.051 & $2.002-2.096$ & 0.034 & $3.593 \pm 0.060$ \\
\hline 8 & $\mathrm{~N} 23.74124$ & E090.39589 & 2.153 & $2.118-2.199$ & 0.027 & $3.772 \pm 0.048$ \\
\hline 9 & $\mathrm{~N} 23.73893$ & E090.79381 & 0.372 & $0.346-0.390$ & 0.017 & $0.651 \pm 0.031$ \\
\hline 10 & N23.73907 & E090.39370 & 0.432 & $0.409-0.476$ & 0.024 & $0.756 \pm 0.043$ \\
\hline 11 & $\mathrm{~N} 23.73931$ & E090.39357 & 0.515 & $0.478-0.564$ & 0.030 & $0.902 \pm 0.053$ \\
\hline 12 & $\mathrm{~N} 23.73940$ & E090.39357 & 0.903 & $0.573-1.082$ & 0.224 & $1.582 \pm 0.392$ \\
\hline 13 & $\mathrm{~N} 23.73941$ & E090.39381 & 1.089 & $1.074-1.152$ & 0.053 & $1.907 \pm 0.606$ \\
\hline 14 & $\mathrm{~N} 23.74027$ & E090.39382 & 1.217 & $1.162-1.287$ & 0.044 & $2.132 \pm 0.077$ \\
\hline 15 & $\mathrm{~N} 23.74052$ & E090.39378 & 1.323 & $1.301-1.346$ & 0.017 & $2.317 \pm 0.029$ \\
\hline 16 & $\mathrm{~N} 23.74099$ & E090.39573 & 1.349 & $1.332-1.359$ & 0.029 & $2.363 \pm 0.052$ \\
\hline 17 & $\mathrm{~N} 23.73852$ & E090.39573 & 2.029 & $2.013-2.040$ & 0.012 & $3.554 \pm 0.021$ \\
\hline 18 & $\mathrm{~N} 23.73851$ & E090.39558 & 2.071 & $2.050-2.091$ & 0.015 & $3.628 \pm 0.026$ \\
\hline 19 & $\mathrm{~N} 23.73838$ & E090.39542 & 0.067 & $0.029-0.122$ & 0.033 & $0.117 \pm 0.058$ \\
\hline 20 & N23.73809 & E090.39519 & 0.164 & $0.147-0.193$ & 0.017 & $0.287 \pm 0.093$ \\
\hline 21 & $\mathrm{~N} 23.73830$ & E090.39449 & 0.226 & $0.205-0.254$ & 0.017 & $0.395 \pm 0.127$ \\
\hline 22 & $\mathrm{~N} 23.73825$ & E090.39422 & 0.272 & $0.256-0.295$ & 0.016 & $0.476 \pm 0.028$ \\
\hline 23 & $\mathrm{~N} 23.73859$ & E090.39350 & 0.319 & $0.304-0.346$ & 0.017 & $0.558 \pm 0.030$ \\
\hline 24 & $\mathrm{~N} 23.73865$ & E090.79332 & 0.375 & $0.343-0.401$ & 0.020 & $0.657 \pm 0.036$ \\
\hline 25 & $\mathrm{~N} 23.74113$ & E090.39587 & 2.226 & $2.202-2.269$ & 0.021 & $3.899 \pm 0.037$ \\
\hline 26 & $\mathrm{~N} 23.74072$ & E090.39584 & 2.286 & $2.261-2.310$ & 0.019 & $4.005 \pm 0.033$ \\
\hline 27 & $\mathrm{~N} 23.73993$ & E090.39634 & 2.348 & $2.320-2.377$ & 0.016 & $4.113 \pm 0.029$ \\
\hline 28 & N23.73967 & E090.39610 & 2.421 & $2.387-2.468$ & 0.026 & $4.241 \pm 0.045$ \\
\hline 29 & $\mathrm{~N} 23.73967$ & E090.39605 & 2.475 & $2.468-2.506$ & 0.017 & $4.336 \pm 0.031$ \\
\hline 30 & $\mathrm{~N} 23.73905$ & E090.36937 & 2.599 & $2.529-2.594$ & 0.143 & $4.553 \pm 0.250$ \\
\hline 31 & N23.73861 & E090.39632 & 3.033 & $3.001-3.063$ & 0.018 & $5.313 \pm 0.033$ \\
\hline 32 & $\mathrm{~N} 23.73862$ & E090.39496 & 3.108 & $3.085-3.151$ & 0.026 & $5.445 \pm 0.045$ \\
\hline
\end{tabular}

Table 1: Gamma-ray dose rate measurement around BSMMU campus from March-May, 2019 in 32 locations

The health risk from absorption by scattered radiation among general public were assessed based on target hazard quotient (THQ) which is the ratio of the potential exposure to a substance and the level at which no adverse effects are expected. It is primarily used by US EPA to assess the health risks of radiation. If, THQ $>1$, the exposed public will likely experience a detrimental effect and if THQ $<1, \mathrm{~A}$ hazard quotient less than or equal to 1 indicates that adverse effects are not likely to occur, and thus can be considered to have negligible hazard.

Hazard Quotient (HQ) around BSMMU is 2.544. This indicates that, the exposed public is under the risk of serious health threat. Radiation dose is a very important parameter to control the quality of the CT, X-ray, PET-scan and many other services within the hospital which are related to nuclear technology.

The term 'Excess life-time cancer risk' (ELCR) is therefore defined as the probability that an individual will develop cancer over his life-time of exposure to radiation.

The frequency of the dose rate (nSv/hr) distribution around BSMMU campus in March-May 2019 is shown in Fig.1. 


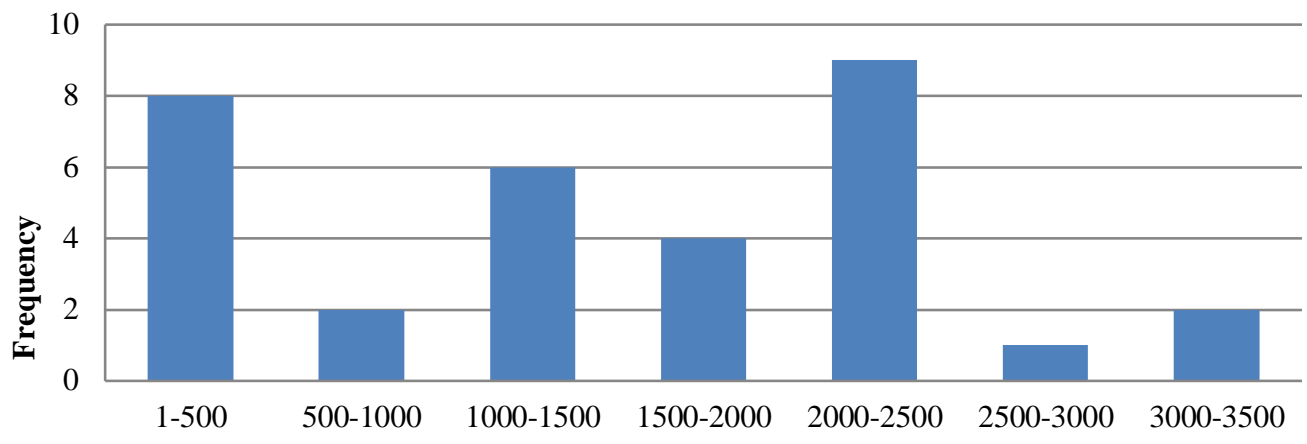

Absorbed Dose rate (nSv/hr)

Fig. 1: The frequency of the dose rate (nSv/hr) distribution around BSMMU campus in March-May 2019

ELCR of public around BSMMU Campus based on annual effective dose are shown in the Fig. 2.

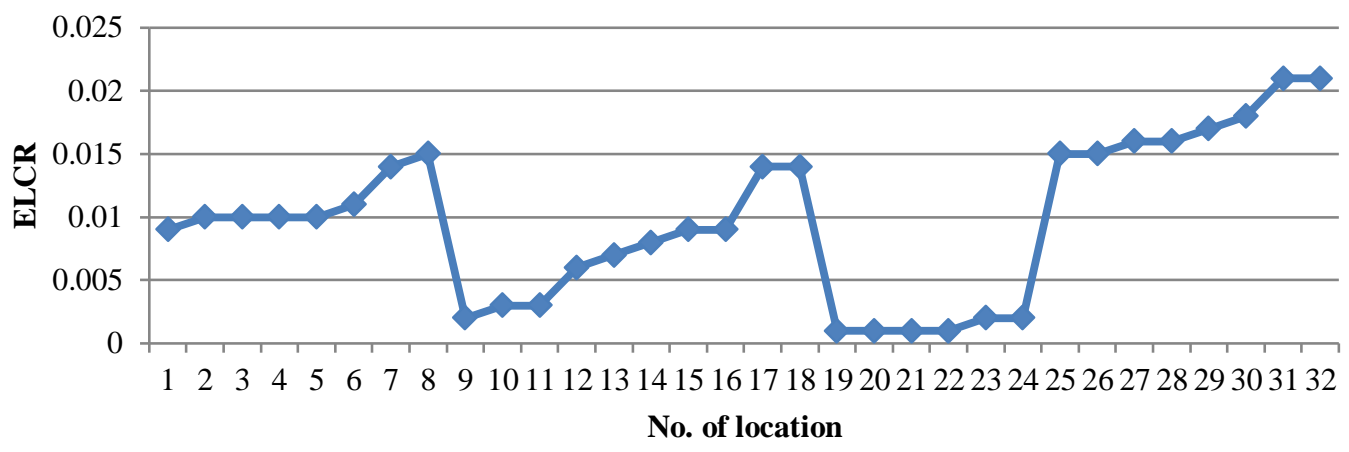

Fig. 2: ELCR of public around BSMMU Campus based on annual effective dose.

From the Table 1, we can say that average annual effective dose around BSMMU campus is $2.544 \pm 1.566$ $\mathrm{mSv}$ where the year limit for general public is $1 \mathrm{mSv}$ and the average ELCR around BSMMU campus is $1 \times 10^{\wedge}-2$. The average ELCR value is higher than the average standard value of $0.291 \times 10^{\wedge}-3$. The average ELCR value around BSMMU means that in every hundred people, one of them is at the risk of cancer caused by the scattered radiation exposure without any knowledge of being exposed to radiation hazard. The development of cancer due to exposure to ionizing radiation is not an immediate effect. It may take several years to develop if it develops at all. It is found in literature (Temaugee et al, 2014) that after exposure to radiation; cancer types may occur with some increasing frequency and can only be detected by epidemiological means. The period between radiation exposure and the detection of cancer is known as the latent period and this could take many years. Most cases, the cancer occurs only when the individual has reached an advanced age. The term 'excess life-time cancer risk' (ELCR) is therefore defined as the probability that an individual will develop cancer over his life-time of exposure to radiation.

\section{CONCLUSION}

Radiation dose is a very important parameter to control the quality of the CT, X-ray, PET scan and linear accelerator services within the hospital. Radiation monitoring helps to ensure the best possible protection of the radiation worker, patients and the general public and provides an immediate indication of incorrect use of technical parameters or equipment malfunction. Around BSMMU campus, average annual effective dose was $2.544 \pm 0.087 \mathrm{mSv}$, whereas the annual effective dose limit for general public is $1 \mathrm{mSv}$ (NSRC Rules, 1997). It is observed from the study that the average annual effective dose of public around BSMMU campus is approximately 2.5 times higher than those of dose limit. The lowest the highest annual effective dose was found to be $0.117 \pm 0.058 \mathrm{mSv}$ and $5.445 \pm 0.045 \mathrm{mSv}$ respectively. Ionizing radiation monitoring and radiation hazard assessment have become issues of great concern for the protection of public and the environment. The International Commission of Radiological Protection (ICRP, 2007) recommends the individual dose must be kept as low as reasonably achievable, and consideration must be given to the 
presence of other sources that may cause simultaneous radiation exposure to the same group of the public. Also, allowance for future sources or practices just is kept in mind so that the total dose received by an individual member of the public does not exceed the dose limit.

\section{ACKNOWLEDGEMENT}

The authors would like to thank concerned personnel of Health Physics Division, Atomic Energy Centre Dhaka for their cooperation. This research is funded by the Ministry of Science and Technology, Government of Bangladesh under the Special Research Allocation Project 2019-2020.

\section{REFERENCES}

BSMMU- Bangabandhu Sheikh Mujib Medical University website, https://old.bsmmu.edu.bd/?page=menu\&content $=138926666081$ (accessed 05 January 2020)

Emelue H. U., Jibiri N. N and Eke B. C. (2014) "Excess Lifetime Cancer Riskdue to Gamma Radiation in and Around Warri Refining and Petrochemical Company in Niger Delta, Nigeria”, British Journal of Medicine \& Medical Research, Vol. 4(13), pp 2590-2598.

EURATOM (1997) "Council directive 97/43, on health protection of individuals against the dangers of ionizing radiation in relation to medical exposure, and repealing Directive 84/466/Euratom”, Official Journal of the European Communities, L 180/22.

Hendry Jolyon $\mathrm{H}$ et al. (2009) "Human exposure to high natural background radiation: what can it teach us about radiation risks?", Journal of Radiological Protection: Official Journal of the Society for Radiological Protection,Vol. 29(2A), pp. A29-42. Doi: 10.1088/0952- 4746/29/2A/S03

http://en.worldstat.info/Asia/Bangladesh (accessed 30 August 2019)

ICRP (2007) "Recommendations of the ICRP: Annals of the ICRP (International Commission on Radiological Protection)", Vol. 37, pp.2-4.

Isam Salih Mohamed Musa (2019) “Environmental Radiation: Natural Radioactivity Monitoring”, Open access peerreviewed chapter, Intech Open Book, pp.1-12, DOI:10.5772/intechopen.85115

NSRC (1997) (The Nuclear Safety and Radiation Control) Rules of Bangladesh (SRO No. 205-Law/97).

Ononugbo C. and Avwiri O. G. (2016) "Evaluation of effective dose and excess lifetime cancer risk from indoor and outdoor gamma dose rate of university of Port Harcourt Teaching Hospital, Rivers State," Scientia Africana, Vol. 15(1). https://www.ajol.info/index.php/sa/article/view/156472

Owner's Manual, GARMIN eTrex HC Series, available at https://static.garmincdn.com/pumac/eTrexLegendHCx_OwnersManual.pdf

Pollycove M. and Cuttler J. M. (2009) "Nuclear energy and health: and the benefits of low-dose radiation hormesis", Dose-response: a publication of International Hormesis Society, Vol. 7(1), pp:52-89. doi:10.2203/ dose-response.08-024.

Qureshi M. U., Muzaffar K. K., Khalid N. B. and Khaloud M. S. (2014) “An Empirical Relationship between In-situ Permeability and RQD of Discontinuous Sedimentary Rocks”, pp. 4781-4791. https://www.scribd.com/document/350401371.

Rao D. D. (2016) “Computation of excess lifetime cancer risk for environmental exposures: Is it needed? - An Opinion", Radiation and Protection Environment, Vol. 39, Issue 1, pp 1-2.

Temaugee S. T., Daniel T. A., Oladejo K. O, and Daniel S. (2014) "Assessment of Public Awareness of the Detrimental Effects of Ionizing Radiation in Kontagora, Niger State”, Nigeria”, International Journal of Science and Technology, Vol. 4(7), pp.134-141.

Trosko James. (1996) "Role of Low-Level Ionizing Radiation in Multi-Step Carcinogenic Process", The Radiation Safety Journal Health Physics, Vol. 70, Issue 6, pp. 812-822.

UNSCEAR (1988) "United Nations Scientific Committee on the Effects of Atomic Radiation, sources, effects and risks of ionizing radiation", (United Nations, New York).

UNSCEAR (1993) "United Nations Scientific Committee on the Effects of Atomic Radiation Sources and Effects of Ionizing Radiation Report to General Assembly, with Scientific Annexes (New York: United Nations).

UNSCEAR (2000) "United Nations Scientific Committee on the Effects of Atomic Radiation. Sources and Effects of Ionizing Radiation Report to General Assembly, with Scientific Annexes (New York: United Nations, United Nations Sales Publication E.00.IX.3).

User Manual GAMMA SCOUT, available at https://www.gamma-scout.com/EN/Handbuch.php 